\title{
Conhecimento e inovação em sistemas locais de produção de revestimentos cerâmicos e os novos desafios da concorrência internacional
}

\author{
Gabriela Scur FEI \\ Renato Garcia EPUSP
}

\section{RESUMO}

Este trabalho tem como objetivo contribuir para a compreensão das novas dinâmicas de geração de conhecimento e inovação em sistemas locais de produção a partir dos desafios da concorrência internacional, por meio da realização de estudos em dois sistemas locais da indústria de cerâmica de revestimento no Brasil, um localizado em Santa Gertrudes/SP e outro em Criciúma/SC. O estudo mostrou que os principais movimentos que caracterizaram o cenário competitivo global no período recente foram a expansão da China no mercado internacional; a expansão da indústria espanhola, fortemente calcada na interação com seus fornecedores de colorifícios; e a perda de participação da indústria italiana, a despeito da forte presença da indústria de máquinas e equipamentos. Mesmo com esse contexto de acirramento da concorrência internacional, a indústria brasileira atravessou um período de expansão, com o crescimento concomitante do mercado doméstico e das exportações. Esse crescimento traduziu-se em um elevado dinamismo da indústria, que contou tanto com a expansão da oferta de revestimentos cerâmicos como com mudanças expressivas nos parâmetros técnico-produtivos das empresas, motivadas em grande parte por um conjunto de benefícios decorrentes da aglomeração das empresas.

\section{Knowledge and innovation in local production systems of ceramic tiles and the new challenges of the international competition}

\begin{abstract}
This paper aims to contribute for the understanding of the new dynamics of knowledge and innovation in local production systems from the strengthening of the international rivalry in the ceramic tile industry, by studying two local systems in the Brazilian ceramic tile industry, one located in Santa Gertrudes/ $S P$ and the other in Criciuma/SC. The research shows that the current international competitive scenario is being characterized by the China's expansion in the world market; the Spanish expansion embedded in the interaction among their glaze suppliers; and the Italian decreasing market share, despite the strong presence of machinery goods industry. In spite of this global rivalry scenario the Brazilian ceramic tile industry had a expansion period with an increase domestic and exports markets. This increasing can be seem in the huge growth of the domestic industry, not only in the expansion of the supply of ceramic tiles but also in important changes in the techno-productive parameters of the firms, motivated by some benefits that came from the clustering of firms.
\end{abstract}

\section{KEY WORDS}

Local production systems, knowledge, innovation, ceramic tile industry. 


\section{INTRODUÇÃO}

O objetivo deste trabalho é investigar os impactos do novo cenário competitivo mundial da indústria de revestimentos cerâmicos sobre a indústria brasileira e, de modo mais específico, sobre a dinâmica de seus dois principais sistemas locais de produção, localizados na região de Criciúma/SC e em Santa Gertrudes/SP.

O trabalho parte da premissa de que a nova organização da cadeia global de valor foi caracterizada por um acirramento do padrão competitivo internacional, especialmente com o crescimento das exportações da China, que se consolidou como o principal produtor mundial de revestimentos cerâmicos. Além do crescimento da indústria chinesa, verificou-se também o crescimento da Espanha no mercado internacional e a perda da participação da indústria italiana. que à configuração da cadeia local e à institucionalidade de apoio à inovação. Por fim, são apresentadas algumas considerações a respeito da dinâmica da indústria brasileira de revestimentos cerâmicos e sua inserção nesse novo cenário competitivo internacional, focalizando especialmente os mecanismos de criação e difusão do conhecimento entre os produtores locais.

\section{CONHECIMENTO, APRENDIZAGEM E INOVAÇÃO}

A importância do conhecimento e da inovação para as empresas tem sido foco crescente de atenção na literatura nos últimos anos. O conhecimento está sendo considerado cada vez mais um recurso crítico das firmas, uma vez que ele é capaz de gerar e fomentar os processos inovativos e de geração de assimetrias concorrenciais (LUNDVALL; JOHNSON, 1994; LAM, 2000; NONAKA; TAKEUCHI, 1995; AMIN; COHENDET, 2004; TEECE, 1998). Parte-se da premissa de que as vantagens competitivas das fir-

A despeito desse contexto de acirramento da concorrência internacional, a indústria brasileira atravessou um período de expansão, com o crescimento concomitante do mercado doméstico e das exportações. Esse crescimento traduziu-se em um elevado dinamismo dessa indústria no Brasil, que contou tanto com a expansão da oferta de revestimentos cerâmicos como com mudanças expressivas nos parâmetros técnico-produtivos das empresas. Nesse processo, deve-se destacar a importância de alguns fatores que exerceram papel fundamental para a criação e difusão de novos conhecimentos e o fomento às atividades inovativas nas empresas, como os fornecedores de colorifícios, os provedores de máquinas e equipamentos e as instituições locais de prestação de serviços. Deve-se ressaltar que a organização produtiva do setor em sistemas locais de produção teve papel fundamental nesse processo, pois facilitou a difusão e a circulação de novos conhecimentos entre os agentes.

Para apresentar e discutir esse argumento, a próxima seção apresenta, resumidamente, os principais elementos do marco teórico acerca dos temas referentes à análise dos sistemas locais de produção da indústria brasileira de revestimentos cerâmicos, como conhecimento, aprendizagem e inovação. Em seguida, são apresentadas as principais características da cadeia global da indústria de revestimentos cerâmicos e novo cenário competitivo internacional. Em seqüência, apresenta-se um breve panorama da indústria brasileira e seus dois principais sistemas locais de produção, com desta- mas derivam-se não somente da sua posição de mercado, mas do desafio em replicar os ativos e, sobretudo, conhecimento, e da maneira na qual eles estão sendo desenvolvidos (TEECE, 1998).

A partir do trabalho pioneiro de Von Hayek (1945), foi realizada uma distinção entre "conhecimento científico" e "conhecimento de uma circunstância particular de tempo e espaço", em que advoga diretamente a necessidade de se especificar os distintos tipos de conhecimento, e suas diferentes dimensões. Nessa mesma linha, Davenport and Prusak (2000) estabelecem uma definição de conhecimento como uma mistura fluida de experiências, valores, informação contextual e insights, que dá origem a uma estrutura para a avaliação e a incorporação de novas experiências e informações.

A diferença existente entre conhecimento e aprendizagem não é sempre clara e, por esse motivo, esses conceitos se confundem. Seguindo a definição de Gavigan et al. (1999), o conhecimento descreve substancialmente um estado ou um potencial de ação e decisão da pessoa, organização ou grupo. Assim, o conhecimento deriva de um processo em que a quantidade de informação alcançada é mediada por um contexto e pelas crenças humanas. Já a aprendizagem é um processo dinâmico, que indica permanentes mudanças no estado do conhecimento, freqüentemente manifestadas pela mudança de entendimento, de decisão ou da ação. De fato, como apontaram Torres et al. (2004), o aprendizado está diretamente associado à forma pela qual as capacita- 
ções são desenvolvidas e adaptadas à mudança no ambiente econômico.

A aprendizagem consiste em um processo de interações, de formação de códigos de práticas, de um regime de avaliação mútua e do compartilhamento de um repertório de histórias, fatos e eventos. Em outras palavras, a aprendizagem pode ser vista como a capacidade de integrar diferentes tipos de conhecimento numa atividade industrial. Lundvall e Johnson (1994) definem a aprendizagem como sendo a aquisição de diferentes tipos de conhecimento, competências e habilidades que fazem um indivíduo ou uma organização obter mais sucesso no alcance de seus objetivos.

O processo de aprendizagem pode acontecer tanto por instrumentos formais - quando ocorre em instituições educacionais com o propósito de disseminar o conhecimento existente - quanto por instrumentos informais, que se baseiam principalmente na experiência. Assim, o crescimento e a difusão de conhecimento, tanto tácito como codificado, tem lugar em firmas e organizações através de atividades de aprendizagem (ARROW, 1962).

O processo de inovação exige a participação e o envolvimento de diversos agentes e fontes de conhecimento e, sendo assim, o aumento de conhecimento pode ser descrito essencialmente como um processo interativo de aprendizagem e inovação. O conhecimento posto em prática é, por esse motivo, capaz de modificar rotinas existentes e gerar valor econômico porque mesmo que o conhecimento tenha característica de bem público, no momento em que se detém ou se absorve o domínio dessa tecnologia, o conhecimento torna-se específico e singular à firma.

Cohen e Levinthal (1990) apontaram a importância da capacidade de absorção na transferência de conhecimento para as firmas. Os autores entendem que a capacidade de absorção consiste na habilidade do receptor em assimilar, valorar e usar o conhecimento transferido. Se o conhecimento não é um bem gratuito e a absorção de informações requer uma capacidade de interpretação e decodificação, o conhecimento e a inovação possuem maiores possibilidades de serem desenvolvidos em redes industriais em que os agentes interagem continuamente. Fazendo isso, eles não somente trocam partes de seus conhecimentos e informações (e também conhecimento tácito), mas socializam seus modelos mentais e seus mapas cognitivos (MCDONALD; BELUSSI, 2003).

É nesse contexto que se insere a discussão sobre a dimensão geográfica do conhecimento e da inovação, já que há uma percepção generalizada na literatura internacional de que a proximidade geográfica tem papel importante na circulação de conhecimentos entre os agentes. Alguns autores, como Audrescht e Feldman (1996) e Breschi e Lisoni (2001), puderam comprovar empiricamente a relação entre geografia e inovação. A proximidade geográfica entre os agentes é capaz de facilitar o processo de circulação das informações e dos conhecimentos por meio da construção de canais próprios de comunicação e de fontes específicas de informação. Esse elemento tem, ainda, o papel de contribuir para o desenvolvimento de novas capacidades organizacionais e tecnológicas, o que leva ao fomento de um processo de aprendizado de caráter local.

\section{Wá uma percepção generalizada na literatura internacional} na circulação de conhecimentos entre os agentes.

A transmissão dos conhecimentos, por meio de transbordamentos (spillovers) ou de formas deliberadas de interação entre os agentes, pode ser capaz de criar mecanismos em que se verifique o processo de criação de novos conhecimentos. Tal resultado ocorrerá quando o conhecimento transferido for combinado com outro conhecimento, originando novas sínteses. A associação dos mecanismos de transferência de conhecimento, somados à combinação cognitiva, tornam-se desse modo fatores decisivos para a inovação. Nesse contexto, os sistemas locais de produção podem representar mecanismos privilegiados para a transmissão desses dispositivos cognitivos. Isso significa que podem vir a formar sistemas interpretativos em que os agentes econômicos pertencentes a um sistema local específico, apesar de sua capacidade cognitiva limitada, têm melhor acesso a um conjunto de conhecimentos dispersos e não-organizados. Isso por que a interação local reforça a comunicação de idéias, descobertas coletivas, crenças compartilhadas, senso coletivo de decisão (collective sense-making), práticas comuns e a propagação de rotinas imitáveis.

Dessa forma, o tipo de conhecimento em que as firmas localizadas em sistemas locais baseiam sua competitividade resulta principalmente da aprendizagem ocorrida através da execução de suas rotinas diárias, experiências adquiridas, acumulação de conhecimento tácito e conversão de conhecimento.

Essas características podem ser verificadas em diversas estruturas produtivas localizadas. Podem ser vistas em estruturas produtivas em que se verificam mecanismos de apoio à interação universidade-empresa em setores hi-tech, como parques tecnológicos e incubadoras de empresas de 
alta tecnologia. Podem ser vistas também em sistemas locais de produção em setores maduros como têxtil, vestuário, calçados, móveis e cerâmica. Neste trabalho, esse conjunto de conceitos é utilizado para a investigação de aglomerações de empresas da indústria de revestimentos cerâmicos, em que podem ser verificados sistemas locais de produção, em todo o mundo, responsáveis por volumes expressivos de produção.

\section{O CENÁRIO INTERNACIONAL DA INDÚSTRIA DE REVESTIMENTOS CERÂMICOS}

Nos últimos anos, a indústria mundial de revestimentos cerâmicos vem passando por modificações importantes no seu padrão de concorrência, a exemplo de outros setores da atividade industrial. A principal característica dessas transformações é o acirramento da competição global, a partir do reposicionamento dos produtores de diversos países, e de suas indústrias domésticas no mercado internacional.

Isso pode parecer paradoxal, mas o acirramento da concorrência internacional na indústria de revestimentos cerâmicos ocorreu no mesmo momento que se assistiu um forte crescimento do consumo mundial de revestimentos cerâmicos, avaliado como sendo da ordem de 5,6\% ao ano na primeira metade da década de $2000^{1}$.

No que se refere à produção mundial, assistiu-se à consolidação da China como o principal produtor mundial de revestimentos cerâmicos, responsável por quase $1 / 3$ da produção física mundial em 2004 (Gráfico 1).

Em seguida, assumiu o segundo posto a Espanha (9,5\% da produção mundial em 2004), ultrapassando a Itália $(8,7 \%)$, que passou a ocupar o terceiro lugar. O quarto maior produtor foi o Brasil, responsável por $8,4 \%$ da produção mundial. Nesse sentido, dos quatro maiores produtores mundiais de revestimentos cerâmicos, apenas a indústria italiana não apresentou taxas positivas de crescimento e a produção local retraiu-se em quase $7 \%$ no período. $\mathrm{O}$ crescimento negativo da indústria italiana está associado, fundamentalmente, à queda na sua participação no mercado internacional (Tabela 1).

Como pode se observar pela tabela, até 2005 a indústria italiana ainda era o principal exportador mundial de revestimentos cerâmicos, responsável por algo em torno de $25 \%$ do comércio mundial total. Porém, nesse período, assistiu-se ao crescimento expressivo da Espanha, que se consolidou como o segundo maior fornecedor mundial desse produto, com $21 \%$ do total do comércio; da China, que atingiu taxas de crescimento bastante expressivas e alcançou o primeiro posto como maior exportador mundial; e do Brasil, cujas exportações mais que dobraram no mesmo período.

Ao contrário dos casos da Itália e da Espanha, em que a produção doméstica está mais fortemente voltada ao mercado externo, tanto no Brasil quanto na China, a produção local esteve historicamente voltada ao atendimento dos respectivos mercados domésticos. Prova disso é que esses países são, ao mesmo tempo, grandes produtores e consumidores mundiais de revestimentos cerâmicos. Porém, a despeito do expressivo consumo doméstico nesses países, ambos têm apresentado crescimento no mercado internacional, com destaque à China, cujas taxas nos últimos anos têm se demonstrado bastante altas.

Em grande parte, o crescimento desses países no mercado internacional esteve associado ao crescimento do consumo mundial de revestimentos cerâmicos, especialmente em países em que o consumo desse produto apresentava patamares bastante reduzidos, em especial os Estados Unidos, que se consolidou como o maior importador mundial. Deve-se apontar que os revestimentos cerâmicos são produtos pouco comercializáveis, especialmente devido ao elevado peso das peças, o que torna os custos de transporte muito altos por causa da reduzida relação valor-peso ${ }^{2}$.

Uma característica importante dessa indústria é a organização da produção sob a forma de aglomerações de empresas, bastante comum no setor e presente em todos os principais produtores internacionais.

$\mathrm{Na}$ China, a produção concentra-se em torno da cidade de Foshan, na província de Guangdong, onde se verifica a existência de cerca de 3.000 empresas, que produzem cerca de $60 \%$ da produção do país e $25 \%$ da produção mundial de revestimentos cerâmicos.

Já na Itália, os produtores de revestimentos cerâmicos estão concentrados na região de Sassuolo, onde estão localizadas cerca de 260 empresas, que são responsáveis por algo em torno de $80 \%$ da produção italiana (MEYER-STAMER et al., 2004). Além dos produtores de revestimentos cerâmicos, o sistema local de Sassuolo destaca-se pela presença e pela competitividade dos produtores de máquinas para a indústria cerâmica, que se aproveitam da proximidade geográfica e cultural com os produtores de revestimentos e beneficiam-se de suas interações com os usuários como a principal fonte para a inovação (RUSSO, 1985).

Como apontado anteriormente, a indústria italiana de revestimentos cerâmicos é a que vem atravessando maiores dificuldades com o acirramento da concorrência internacional, como mostra a sua participação decrescente no mercado mundial. Porém, como resposta a esse fenômeno, diversas empresas italianas têm procurado realizar investimentos por 
meio do estabelecimento de unidades produtivas em outros países. Segundo Gambuli (2001), 16 empresas com capital majoritariamente italiano operam fora do país, algumas com mais de uma unidade produtiva. Dentre elas, três estão localizadas nos Estados Unidos, seis na França, duas na Espanha, uma em Portugal, uma na Alemanha, uma na Suécia, uma na Finlândia e uma na República Checa.

Essa é uma das razões da perda da participação italiana no mercado internacional, já que parte do mercado que era abastecido pela indústria italiana passou a ser atendido por produção local de empresas de capital italiano. Além disso, se por um lado essa estratégia fortalece a competitividade das empresas italianas, ela tem como efeito secundário o enfraquecimento do sistema local de Sassuolo, já que representa redução da produção e do emprego local. As empresas que decidiram estabelecer unidades produtivas no exterior abdicaram de ao menos parte dos benefícios que são proporcionados pela aglomeração dos produtores em Sassuolo e tentaram compensar essa perda com a maior proximidade de seus mercados consumidores.

$\mathrm{Na}$ Espanha, também pode se perceber a existência de um importante sistema local de produção de revestimentos cerâmicos, localizado na região em torno da cidade de Castellón. Nessa região estão localizadas cerca de 240 empresas, predominantemente de pequeno e médio porte, que são responsáveis por $90 \%$ da produção espanhola.

A exemplo da experiência italiana, o sistema local de Castellón destaca-se não apenas pela presença concentrada de produtores de revestimentos cerâmicos, mas também pela existência dos chamados colorifícios, que são empresas especializadas na fabricação de produtos químicos utilizados na indústria cerâmica, como fritas e corantes. Também nesse caso, o desenvolvimento da produção de colorifícios relaciona-se com o aproveitamento das possibilidades de intensificação das relações usuário-produtor, a partir da proximidade geográfica e cultural entre as empresas. Devese apontar ainda que a presença e o desenvolvimento dos produtores de colorifícios é particularmente importante para a indústria cerâmica, já que a produção de insumos é uma fonte crescentemente importante para a inovação nessa indústria.

O sistema local de Castellón apresentou, a partir do início dos anos 1990, um forte dinamismo, baseado sobretudo na excelência tecnológica, expressada pelos fortes investimentos em máquinas e equipamentos e no desenvolvimento de uma importante indústria de colorifícios. Ao contrário da experiência italiana, as empresas de Castellón são mais especializadas, o que contribuiu para intensificar as relações interativas com seus fornecedores. No caso da indústria fornecedora de bens de capital, podem-se notar as intensas

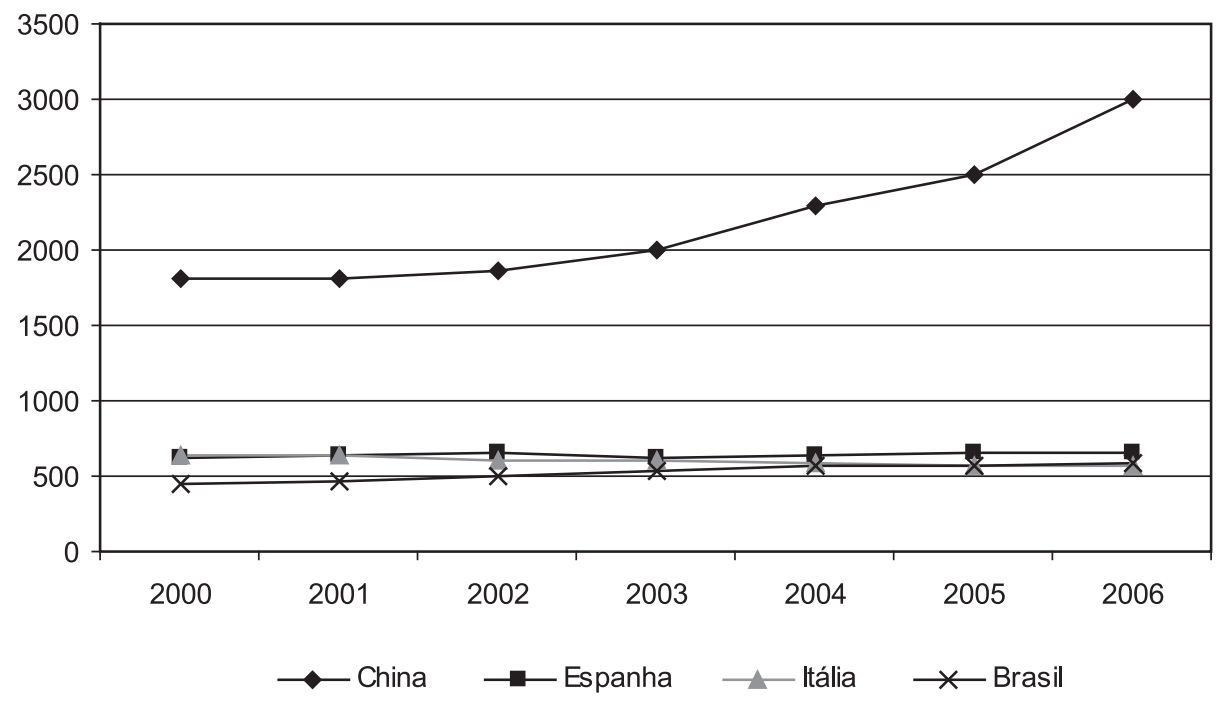

Gráfico 1: Principais produtores mundiais.

Fonte: ASCER - Associação dos Produtores de Cerâmica de Revestimentos da Espanha, 2006 e ANFACER - Associação Nacional dos Fabricantes de Cerâmica para Revestimento, 2008. Os dados estão apresentados no Anexo. 
relações das empresas de Castellón com os fabricantes italianos de máquinas e equipamentos.

Já no caso da indústria de fritas e corantes, pode-se observar a importância do desenvolvimento de produtores locais. Segundo Meyer-Stamer et al. (2004), ao final da década de 1990 existiam 24 empresas locais de fritas e corantes, muitas delas com unidades produtivas no exterior. Esse ponto é particularmente importante e representa uma vantagem competitiva especial dos produtores espanhóis por conta das mudanças do padrão competitivo da indústria de revestimentos cerâmicos. Nas últimas décadas, pode-se notar o deslocamento das atividades de desenvolvimento de produto e design dos produtores de revestimentos para os fornecedores de fritas e corantes, que passaram a se ocupar de grande parte desses esforços. Um elemento que comprova essa impressão é, como apontado por Meyer-Stamer et al. (2004), que os departamentos de desenvolvimento de produto que podem ser verificados nos colorifícios são bem mais expressivos do que os das empresas de revestimentos cerâmicos.

Em termos do cenário competitivo internacional, o crescimento da participação da indústria espanhola está fortemente relacionado com esses elementos, já que boa parte da produção do país está concentrada no sistema local de Castellón. O elevado conteúdo de conhecimento na produção de revestimentos cerâmicos, especialmente de conhecimentos tácitos, tem ensejado ganhos significativos para a indústria local, com efeitos importantes sobre sua participação no comércio mundial. Além disso, esse padrão de resposta das empresas espanholas ao acirramento do processo de concorrência internacional tem se revelado bastante bem-sucedido, já que essa indústria vem conquistando espaços importantes no mercado mundial mesmo com o forte avanço das exportações oriundas da China.

\section{A INDÚSTRIA BRASILEIRA DE REVESTIMENTOS CERÂMICOS}

O Brasil é o segundo maior mercado consumidor de revestimentos cerâmicos do mundo, atrás apenas da China, e configura-se como o quarto maior produtor mundial (ANFACER, 2008). O desenvolvimento da produção de revestimentos cerâmicos no Brasil está relacionado a diversos fatores, entre os quais se destacam o vasto mercado consumidor doméstico, a abundância de matéria-prima natural, a disponibilidade de energia e o acesso a tecnologias de processo embutidas em máquinas e equipamentos.

Na década de 1990, a indústria brasileira de revestimentos cerâmicos apresentou um expressivo crescimento da produção, associado, principalmente, à elevação do consumo desse produto no país (ver Tabela 2).

Em grande parte, esse crescimento do consumo de revestimentos cerâmicos no Brasil esteve ligado ao incremento da renda doméstica nesse período. Porém, não se pode deixar de mencionar a importância da redução dos preços do produto no mercado doméstico, resultado do acirramento da concorrência nesse mercado, o que inclui processos vultosos de reestruturação das empresas e expressivos ganhos de produtividade.

A indústria brasileira de revestimentos cerâmicos, ao contrário das principais experiências internacionais, desenvolveu um parque fabril em que o principal método de fabricação é o processo via seca (cerca de $2 / 3$ da produção), segundo a Anfacer (2008), menos oneroso e com padrões de qualidade compatíveis com as exigências das normas internacionais ${ }^{3}$.

$\mathrm{O}$ parque produtivo da indústria de revestimentos cerâmicos no Brasil é constituído, de acordo com a Anfacer (2008), por 94 empresas e 117 plantas industriais distribuí-

Tabela 1: Exportações Mundiais - em milhões de $\mathbf{m}^{2}$.

\begin{tabular}{cccccccc}
\hline Países & 2000 & 2001 & 2002 & 2003 & 2004 & 2005 & 2006 \\
\hline China & 24,3 & 53,1 & 124,8 & 206,4 & 270 & 310 & 450 \\
Itália & 436,3 & 440,7 & 437,7 & 417,6 & 412,5 & 392 & 396 \\
Espanha & 311,5 & 339 & 356,5 & 335,7 & 340,5 & 342 & 114,4 \\
Brasil & 56,8 & 59,5 & 73,9 & 103,6 & 125,8 & 88 & 93 \\
Turquia & 61,5 & 56,4 & 72,2 & 84,1 & 85,5 & n.d. \\
Outros & 263,4 & 261,7 & 271,8 & 320,4 & 324,9 & n.d. & n.d. \\
\hline TOTAL & $1.153,8$ & $1.210,4$ & $1.336,9$ & $1.467,8$ & $1.607,4$ & n.d. \\
\hline
\end{tabular}

Fonte: ASCER, 2006. 
das por todas as regiões do país, que empregam cerca de 25 mil trabalhadores. A produção de revestimentos cerâmicos no Brasil espalha-se por todo o país, mas está fortemente concentrada em quatro regiões principais (ver Mapa 1): a região de Criciúma, no estado de Santa Catarina; a região da Grande São Paulo, ao redor da região mais industrializada do país e onde se encontra o principal mercado consumidor; a região de Mogi Guaçu, e a região de Santa Gertrudes, ambas no interior do estado de São Paulo. Juntas, essas regiões respondem por cerca de $90 \%$ da produção doméstica.

Entre essas regiões produtoras, pode-se verificar a existência de duas aglomerações industriais que se configuram claramente como sistemas locais de produção: o sistema local de Criciúma e o de Santa Gertrudes. Essas duas experiências serão analisadas nas próximas seções.

\section{SISTEMAS LOCAIS DE PRODUÇÃO NA INDÚSTRIA BRASILEIRA DE REVESTIMENTOS CERÂMICOS}

As duas principais aglomerações de produtores de revestimentos cerâmicos no Brasil, as regiões de Criciúma e de Santa Gertrudes, concentram em torno de 3/4 da produção doméstica total. Nas próximas seções, serão apresentadas as principais características, vantagens e desvantagens de cada uma delas.

\subsection{0 sistema local de Criciúma}

A indústria de revestimentos cerâmicos de Criciúma configura-se como o mais tradicional pólo produtor do Brasil. Algumas das empresas locais, que ainda atuam no setor, entraram em operação na década de 1950. Mas o período de maior dinamismo deu-se nos anos 1970 e 1980, atrelado ao crescimento da demanda doméstica por revestimentos cerâmicos. Esse período de elevado dinamismo cessou na década de 1990, quando os produtores locais enfrentaram uma grave crise de demanda associada ao acirramento da concorrência no mercado doméstico, a partir do crescimento da oferta de produtos cerâmicos, oriundo especialmente do sistema local de Santa Gertrudes ${ }^{4}$.

Essa crise ensejou movimentos expressivos de reestruturação dos produtores locais, especialmente entre as grandes empresas, que envolveu a desativação de linhas antigas de produção e abertura de novas, ampliação, construção e aquisição de unidades industriais, modernização de equipamentos, além de mudanças nas estruturas organizacionais e de gestão. Especificamente, a modernização de equipamentos trouxe alguns aprimoramentos tecnológicos que tiveram papel importante para o incremento da competitividade das empresas locais, como a passagem da biqueima porosa para o gres porcelanato; a redução das perdas e diminuição das camadas e uso de matéria-prima mais econômica no que se refere ao esmalte; e a substituição dos fornos, reduzindo o consumo de gás por metro quadrado e a redução de custos através da utilização de técnicas automatizadas de embalagem (LEMOS; VIVONA, 1997). Os resultados desse processo de racionalização produtiva e de modernização do parque de máquinas foram uma elevação importante da produtividade, além de uma maior concentração da produção em unidades industriais maiores.

Todavia, esse processo de reestruturação e modernização tecnológica não impediu a queda na participação relativa dos produtores locais no mercado doméstico. O principal vetor dessa retração da participação das empresas locais foi a expansão dos produtores de Santa Gertrudes, que passaram a ocupar o posto de principal pólo produtor de revestimentos cerâmicos do Brasil.

Dentro desse processo de reestruturação produtiva, houve também a desverticalização de diversas empresas locais. Antes desse período, muitas empresas exerciam internamente as atividades de produção de colorifício e esmaltação, o que significava que as empresas eram obrigadas a manter dentro de seus limites atividades ligadas à indústria química. A partir dos anos 1990, as empresas locais externalizaram essa etapa da produção $0^{5}$. Ao mesmo tempo em que houve a externalização das atividades de esmaltação, houve também a entrada expressiva de novos agentes na indústria de colorifícios.

ma característica importante dessa indústria é a organização da produção sob a forma de aglomerações de empresas

Diversas empresas, muitas delas espanholas, oriundas de Castellón, instalaram unidades produtivas na região, o que permitiu aos produtores locais intensificar as relações com os seus fornecedores, com efeitos positivos em termos das atividades inovativas das empresas locais. As empresas de colorifícios passaram não apenas a vender seus produtos aos fabricantes de revestimentos cerâmicos, mas também a oferecer um conjunto de produtos e serviços correlatos entre os quais design de peças e assessoria no processo de fabricação, especialmente no que se refere à adaptação de novos produtos e processos às matérias-primas e às demais condições do fabricante. 
No caso das empresas espanholas, por exemplo, as filiais no Brasil utilizavam muitas vezes o know-how das suas matrizes, e dos seus centros de $\mathrm{P} \& \mathrm{D}$, para resolver problemas surgidos nos processos produtivos de seus clientes no Brasil. No campo do design, mantêm estreita relação com importantes centros internacionais e com os centros de design de seus respectivos grupos e repassam essas competências aos produtores domésticos, não apenas por meio dos produtos que são adquiridos, como também por uma série de serviços correlacionados e de elevado valor (FERRAZ, 2002).

Isso, todavia, tem um lado negativo para a indústria brasileira, como apontam alguns autores como Ferraz (2002). Essas estratégias das empresas de colorifícios, principalmente das empresas estrangeiras no Brasil, dificultam e desestimulam a endogenização de competências em design entre os produtores domésticos de revestimentos cerâmicos. Entretanto, vale ressaltar que cada vez menos a indústria cerâmica internaliza esse tipo de capacitação, já que os colorifícios têm se demonstrado extremamente capazes e muito mais velozes na geração, adoção e difusão de inovações na indústria cerâmica.

Outro vetor importante do movimento de reestruturação da indústria de revestimentos cerâmicos da região de Criciúma foi a modernização do parque produtivo das empresas locais, por meio de investimentos vultosos voltados à compra de máquinas e equipamentos. Isso implicou em um elevado volume de importações de bens de capital, provenientes sobretudo da Itália, principal provedor mundial de máquinas e equipamentos para a indústria cerâmica. Normalmente, as unidades dessas empresas não são fabricantes de máquinas e equipamentos no Brasil, mas exercem papel importante para a corporação, tanto no que se refere à distribuição de peças para reposição, como também por aproximar a empresa, e seus produtos, de seus usuários no país ${ }^{6}$.

Tabela 2: Produção, exportação, consumo aparente e capacidade instalada da indústria brasileira de revestimentos cerâmicos.

\begin{tabular}{|c|c|c|c|c|c|c|c|}
\hline \multirow[t]{2}{*}{ Ano } & \multicolumn{5}{|c|}{ Milhões de m² } & \multicolumn{2}{|c|}{$\%$} \\
\hline & Produção & Exportações & $\begin{array}{l}\text { Consumo } \\
\text { Aparente* }\end{array}$ & $\begin{array}{l}\text { Vendas } \\
\text { internas }\end{array}$ & $\begin{array}{l}\text { Capacidade } \\
\text { Instalada }\end{array}$ & $\begin{array}{l}\text { Exportações/ } \\
\text { Produção }\end{array}$ & $\begin{array}{l}\text { Produção/ } \\
\text { Capacidade }\end{array}$ \\
\hline 1990 & 172,8 & 12,7 & 160,1 & n.d. & 300,0 & 7,3 & 57,6 \\
\hline 1991 & 166,0 & 13,9 & 152,1 & 149,9 & 312,0 & 8,4 & 53,2 \\
\hline 1992 & 202,7 & 21,1 & 181,6 & 179,1 & 312,0 & 10,4 & 65,0 \\
\hline 1993 & 242,9 & 25,6 & 217,3 & 214,1 & 320,0 & 10,5 & 75,9 \\
\hline 1994 & 283,5 & 29,7 & 253,8 & 259,9 & 353,0 & 10,5 & 80,3 \\
\hline 1995 & 295,0 & 29,4 & 265,6 & 261,6 & 362,0 & 10,0 & 81,5 \\
\hline 1996 & 336,4 & 27,9 & 308,5 & 309,1 & 385,0 & 8,3 & 87,4 \\
\hline 1997 & 383,3 & 29,6 & 353,7 & 339,8 & 385,0 & 7,7 & 99,6 \\
\hline 1998 & 400,7 & 34,6 & 366,1 & 358,7 & 455,0 & 8,6 & 88,1 \\
\hline 1999 & 428,5 & 42,6 & 385,9 & 383,3 & 492,0 & 9,9 & 87,1 \\
\hline 2000 & 452,7 & 56,7 & 396,0 & 393,3 & 536,7 & 12,5 & 84,3 \\
\hline 2001 & 473,4 & 59,5 & 413,9 & 416,3 & 556,9 & 12,6 & 85,0 \\
\hline 2002 & 508,3 & 73,9 & 434,4 & 456,3 & 564,4 & 14,5 & 90,1 \\
\hline 2003 & 534,0 & 103,5 & 430,5 & 421,0 & 571,4 & 19,4 & 93,5 \\
\hline 2004 & 565,6 & 125,8 & 439,8 & 448,4 & 621,6 & 22,2 & 91,0 \\
\hline 2005 & 568,1 & 113,8 & 454,3 & 442,8 & 650,7 & 20,0 & 87,3 \\
\hline 2006 & 594,2 & 114,5 & 479,7 & 483,6 & 672,4 & 19,3 & 88,4 \\
\hline 2007 & 637,1 & 102,1 & 535,0 & 534,7 & 698,0 & 16,0 & 91,3 \\
\hline
\end{tabular}

* Produção menos Exportações; dado o baixo montante das Importações.

Fonte: Elaboração própria a partir de Anfacer e Ferraz (2002). 
Esse ponto foi objeto de outro trabalho (SCUR; GARCIA, 2008). A existência de vínculos fortes entre os produtores de revestimentos cerâmicos de Santa Catarina e fornecedores externos de insumos revela uma característica muito importante do sistema local, que é a sua capacidade de apropriar-se de fluxos externos de conhecimento, oriundos de outras regiões, que são incorporados pelos agentes locais por meio de processos de aprendizado interativo. Belussi et al. (2006), em seu estudo sobre os sistemas locais italianos, chamaram esse processo de aprendizado pelos limites ("learning at the boundaries"), em que os agentes locais são capazes de criar vínculos externos que exercem papel muito importante para o fomento de processos endógenos de aprendizado e inovação.

A partir desses esforços de reestruturação produtiva, tecnológica e organizacional, as empresas de revestimentos cerâmicos passaram a focalizar seus esforços na sua atividade principal, a produção de revestimentos cerâmicos. Ao mesmo tempo, isso permitiu a abertura e o crescimento de novas empresas em setores correlatos, como é o caso da indústria de colorifícios, o que promoveu um incremento da complexidade do sistema local. Em meados da década de 2000, o sistema local passou a ser composto por cerca de 10 empresas de revestimentos cerâmicos, 14 provedores de insumos (entre produtores e distribuidores, mas todos com diversos serviços que são prestados às empresas cerâmicas) e 5 fabricantes de máquinas e equipamentos e de peças para reposição 7 .

Além disso, esse aumento da complexidade do sistema local de Criciúma criou uma demanda mais qualificada por serviços pelas empresas locais, o que permitiu o surgimento de novos espaços para a atuação das instituições locais vinculadas ao setor empresarial. De fato, as transformações que atingiram o sistema local de Criciúma ao longo da década de 1990 induziram o surgimento de novas instituições e de iniciativas de apoio inovadoras.

Um exemplo claro desse movimento foi a criação do Centro de Tecnologia em Cerâmica - CTC, em 1995, através de uma ação conjunta entre a associação local dos produtores (Sindiceram - Sindicato da Indústria Cerâmica de Criciúma e Região), o Senai local e a Universidade Federal de Santa Catarina. O estabelecimento desse centro tecnológico teve como objetivo principal a criação de um organismo capaz de prestar serviços técnicos e tecnológicos aos produtores locais, como análises de materiais, ensaios e testes laboratoriais, certificação de produtos e de processos produtivos, informações tecnológicas, além de desenvolver projetos de $\mathrm{P} \& \mathrm{D}$ em conjunto com empresas locais ligadas à cadeia produtiva.

Além disso, o laboratório do Centro Tecnológico foi credenciado pelo INMETRO, permitindo-lhe certificar as empresas com o selo ISO 9001, além de emitir um certificado do produto acabado reconhecido internacionalmente. O Centro Tecnológico possui ainda uma linha de produção experimental, denominada Planta Piloto, que é capaz de simular todo o processo produtivo cerâmico para o desenvolvimento de massas, esmaltes e produtos cerâmicos em escala semi-industrial.

\section{$A$ s empresas de colorifícios passaram antes de revestimentos cerâmicos.}

Outra instituição que foi criada no bojo da reestruturação do sistema local ao longo dos anos 1990 foi o Curso Superior de Tecnologia Cerâmica, criado em 1996, resultado de uma ação conjunta da associação local dos produtores e uma universidade local (UNESC). Essa instituição de ensino somou-se a duas outras instituições de formação de mão-de-obra, porém de nível técnico. Uma delas é voltada para a formação de pessoal de nível técnico, o Colégio Maximiliano Gaidzinski. Essa escola configurou-se como a principal instituição de formação de mão-de-obra técnica do país, fornecendo técnicos para empresas do todo o Brasil. O outro curso de nível técnico da região é ministrado pela unidade local do Senai.

Por fim, destaca-se a existência do Laboratório Interdisciplinar de Materiais da Universidade Federal de Santa Catarina (LabMat-UFSC). Apesar de localizar-se no município de Florianópolis, capital do estado de Santa Catarina e distante cerca de $200 \mathrm{~km}$ de Criciúma, o laboratório possui diversas linhas de pesquisas voltadas ao desenvolvimento de novos materiais cerâmicos, desde matérias-primas, processos de produção e produtos cerâmicos tradicionais, incluindo materiais vidrados e vitrocerâmicos.

Nota-se, nesse sentido, a presença de um amplo aparato institucional de apoio aos produtores locais, tanto no que se refere à formação e qualificação da mão-de-obra, como no concernente aos serviços técnicos e tecnológicos e no desenvolvimento de projetos de pesquisa vinculados às atividades dos produtores locais. Porém, diversos autores (MEYER-STAMER et al., 2004; FERRAZ, 2002) apontam que dificuldades de relacionamento entre as empresas e as instituições locais têm impedido o estabelecimento de projetos conjuntos mais numerosos e duradouros entre os agentes. Por exemplo, são muito reduzidos os projetos que vêm sendo realizados entre empresas locais e o Centro Tecnológico, cuja atuação tem se restringido à prestação 
de serviços técnicos e tecnológicos como ensaios e testes laboratoriais. Mesmo fenômeno ocorre nas interações universidade-empresa.

Assim, apesar da resposta das empresas locais diante do acirramento da concorrência no mercado doméstico ter indicado um incremento dos esforços e das atividades inovativas, as empresas não se aproveitam plenamente do aparato institucional disponível. Isso faz com que elas não se beneficiem de todas as externalidades positivas que são geradas pela aglomeração dos produtores.

\subsection{0 sistema local de Santa Gertrudes}

O sistema local de produção de revestimentos cerâmicos de Santa Gertrudes, e da região contígua, está localizado no estado de São Paulo, no seio do maior mercado consumidor do país, inclusive de revestimentos cerâmicos. Na região de Santa Gertrudes, estão localizadas cerca de 45 empresas de revestimentos cerâmicos, que respondem por cerca de metade da produção física do país. A origem do sistema local esteve fortemente vinculada à disponibilidade de argila que era utilizada para a produção de tijolos e telhas em pequenos empreendimentos industriais. A partir da década de 1980, no entanto, as empresas realizaram investimentos na produção de revestimentos cerâmicos, utilizando a matéria-prima disponível para a fabricação de revestimentos voltados a consumidores de média e baixa renda.

to acelerado do sistema local de Santa Gertrudes foram os investimentos expressivos das empresas na modernização de seu processo produtivo, especialmente por meio da aquisição de máquinas e equipamentos mais atualizados tecnologicamente. Além da aquisição de modernos fornos utilizados no processo de queima, as empresas adquiriram novos sistemas de preparação da massa, que permitiram o alcance de menores granolumetrias e proporcionaram melhorias importantes no processo de granulação e umidificação. Vale salientar o papel importante exercido pelos fornecedores, sobretudo italianos, de máquinas e equipamentos para os produtores locais, já que permitiram a modernização acelerada das empresas locais e, especialmente, a adaptação dos equipamentos às características do processo de produção local.

Desse modo, o processo de crescimento dos produtores de revestimentos cerâmicos de Santa Gertrudes envolveu a criação e a reprodução de capacitações importantes dos produtores na área de manufatura, como fica claro no processo de modernização tecnológica dos processos de fabricação.

Porém, além desses elementos, é preciso apontar ainda a importância de outros dois fatores que contribuíram para esse processo de crescimento, que são os fornecedores de colorifícios e as instituições locais de prestação de serviços, especialmente o CITEC - Centro de Inovação Tecnológica.

No caso dos colorifícios, seu papel foi particularmente importante devido às novas características do processo de concorrência na indústria de revestimentos cerâmicos, em que as tarefas de desenvolvimento de produto foram em grande parte transferidas aos for-

Esses investimentos na capacidade produtiva proporcionaram às empresas locais um elevado crescimento na década de 1990, aproveitando sobremaneira a elevação da demanda por revestimentos cerâmicos no Brasil ${ }^{8}$. Dois elementos tiveram papel decisivo nesse processo de crescimento.

Primeiro, destaca-se a importância da disponibilidade de matéria-prima a custos baixos na região, cujas características permitem que as empresas locais utilizem o processo por via seca. Esse processo de produção de revestimentos cerâmicos, por um lado, possui características técnicas ligeiramente inferiores ao processo de via úmida, mas por outro apresenta custos sensivelmente mais baixo ${ }^{9}$. Esses custos mais reduzidos estão associados às facilidades de obtenção e de extração da argila da natureza e aos menores custos de produção, dado que o processo de produção se dá em tempo muito mais reduzido e com farta economia de energia ${ }^{10}$.

O segundo elemento decisivo no processo de crescimen- necedores de fritas e corantes. Como os produtores de revestimentos cerâmicos de Santa Gertrudes não possuíam departamentos internos de desenvolvimento de produto, eles puderam contar com os serviços de seus provedores, o que os desobrigou de estabelecer estruturas próprias na área do desenvolvimento. E dessa forma os produtores locais puderam incorporar atributos diferenciados aos seus produtos mesmo na ausência de processos prévios de acumulação de capacitações nessa área. Além disso, vale lembrar que em geral os produtores locais atendem um mercado de consumidores de média e baixa renda, em que os requisitos de sofisticação do produto são muito menos expressivos. Isso teve um efeito importante na aceleração do crescimento dos produtores locais, que não precisaram desenvolver capacitações próprias na área do desenvolvimento de produto e foram capazes de se apropriar de um conjunto de capacitações externas. 
Já o papel do centro tecnológico (CITEC) foi ainda mais expressivo. Inaugurado em 2002, em Santa Gertrudes, o CITEC foi criado através de uma parceria entre a associação dos produtores e o poder público local, com o apoio do Centro Cerâmico do Brasil (CCB), principal instituição brasileira de prestação de serviços às empresas do setor. Inicialmente foi idealizado para a realização de ensaios para a certificação de produtos, seguindo as normas brasileiras e internacionais dessa indústria. O centro tecnológico estava inserido dentro da estrutura do Centro Cerâmico do Brasil, que desde 1998 já era uma entidade credenciada para emitir laudos de certificação de produtos.

Todavia, o papel do centro tecnológico de Santa Gertrudes, o CITEC, em muito ultrapassou as tarefas de certificação de produto, já que sua atuação passou a se pautar também por diversas outras atividades relacionadas com o estímulo e a assessoria à adoção de melhorias no processo produtivo das empresas locais e a assistência técnica e tecnológica. Para atingir os níveis determinados de qualidade e padronização exigidos pelas normas, as empresas foram obrigadas a adotar melhorias em seus processos produtivos, tarefa em que contaram com o apoio decisivo do Centro Tecnológico.

O Centro Tecnológico abriga ainda o Núcleo de Inovação em Produtos e Design, que possui infra-estrutura física, equipamentos e recursos humanos qualificados para a criação e execução de projetos decorativos, desenvolvimento e difusão de metodologias de gestão de projetos inovativos nas empresas, realização de pesquisas iconográficas, especialmente no que se refere à tentativa de estimular a criação de identidade própria aos produtos dos fabricantes locais. Além disso, nele se realizam projetos de pesquisa e desenvolvimento de novos insumos, materiais e produtos, alguns em cooperação com universidades ${ }^{11}$.

Nesse sentido, o papel do centro tecnológico no fomento ao desenvolvimento de capacitações locais foi fundamental. Apesar de sua atuação estar inicialmente ligada a atividades de certificação de produtos, o CITEC teve um papel muito mais abrangente, sobretudo no que se refere às expressivas melhorias que foram verificadas em termos de controle de processo e gestão de manufatura. Isso ocorreu porque as empresas locais, para atingir os requisitos técnicos necessários em seus produtos, e alcançar os níveis exigidos pelos sistemas de certificação, foram forçadas a adotar melhorias em seus processos produtivos, e puderam contar com a colaboração decisiva do centro tecnológico.

Deve-se observar no entanto que, a despeito da existência de uma área de inovação de produto e design, a atuação mais importante da instituição ficou limitada à função de manufatura, com poucos avanços no que se refere a atividades inovativas e de desenvolvimento de produto. A principal razão para isso parece residir no fato de que os produtores de revestimentos cerâmicos de Santa Gertrudes não internalizaram capacidades mais expressivas na área do desenvolvimento de produto, atividade que ficou sob responsabilidade dos seus fornecedores de colorifícios.

\section{CONSIDERAÇÕES FINAIS SOBRE OS PROCESSOS DE APRENDIZADO E INOVAÇÃO}

Diante do panorama competitivo global da indústria de revestimentos cerâmicos e do cenário do setor no Brasil, é preciso analisar os principais elementos que determinam a dinâmica da indústria brasileira, e mais especificamente dos sistemas locais de produção de revestimentos cerâmicos de Criciúma e Santa Gertrudes.

O Brasil tem uma participação pouco expressiva no cenário mundial. Especialmente por conta de seu vasto mercado doméstico, a produção de revestimentos cerâmicos atende predominantemente a demanda interna. Nesse sentido, mesmo que nos últimos anos tenha sido possível perceber incrementos nas exportações, o crescimento expressivo da indústria brasileira de revestimentos cerâmicos nas últimas décadas esteve fortemente associado à expansão da demanda doméstica. Porém, como exposto nas seções anteriores, o sistema local de Santa Gertrudes apresentou taxas de crescimento bastante elevadas, o que implicou em um estreitamento da faixa de atuação dos outros produtores e até mesmo na retração na participação no mercado. Esse é um dos motivos que explicam a expansão das vendas externas, já que os principais agentes nesse processo de busca de mercados internacionais foram, predominantemente, as empresas do sistema local de Criciúma, que foram pressionadas pelo acirramento da concorrência no mercado doméstico em virtude do crescimento das empresas de Santa Gertrudes.

Nesse ponto, percebe-se uma das diferenças marcantes entre a indústria brasileira de revestimentos cerâmicos e as experiências de outros países como Itália e Espanha, que também apresentam uma estrutura industrial calcada na existência de sistemas locais de produção. Tome-se, por exemplo, a comparação com a indústria italiana. A despeito do expressivo crescimento das exportações brasileiras de revestimentos cerâmicos nos últimos anos, o coeficiente de exportações no Brasil alcançou, em 2004, pouco mais de $20 \%$ da produção doméstica total. A indústria italiana, por seu turno, apresentou no mesmo ano um coeficiente exportador de cerca de $70 \%$, o que denota claramente sua expressiva inserção internacional e a importância do mercado externo como destino da produção local ${ }^{12}$. 
Por outro lado, as importações de revestimentos cerâmicos no Brasil são praticamente inexpressivas. Isso mostra que, a despeito do vasto mercado doméstico brasileiro, que se configura como o segundo maior mercado mundial, e do acirramento da concorrência no mercado internacional, não há esforços expressivos de empresas estrangeiras no Brasil. Além disso, as empresas brasileiras, que são detentoras de marcas importantes no mercado doméstico, não se utilizam de esquemas de subcontratação internacional para o suprimento de mercadorias, fato cada vez mais comum em indústrias como vestuário e calçados. Uma das explicações para isso está associada às características físicas desse produto, que apresenta uma relação valor/peso pouco expressiva. Ademais, no caso da indústria brasileira, houve um crescimento expressivo da oferta e da capacidade produtiva, que foi acompanhado por melhorias nos sistemas de produção e por ganhos de produtividade.

Nesse sentido, o crescimento da China no mercado internacional não provocou efeitos mais expressivos sobre a dinâmica da indústria brasileira de revestimentos cerâmicos, já que não se verificaram incrementos mais vultosos nas compras externas. No mercado internacional, em que se percebeu o crescimento da indústria chinesa como um grande fornecedor internacional, com efeitos importantes sobre o padrão competitivo da cadeia global, a indústria brasileira também foi pouco afetada.

Por fim, é preciso ressaltar a origem dos fluxos de conhecimento e a acumulação de capacitações na indústria brasileira de revestimentos cerâmicos e, mais especificamente, em seus dois sistemas locais mais importantes. Como foi apontado, o crescimento dessa indústria nos últimos anos esteve acompanhado por mudanças qualitativas importantes, no que se refere à criação e acumulação de capacitações técnico-produtivas. Esse processo, ressalte-se, foi particularmente importante no sistema local de Santa Gertrudes, que apresentou mais elevado dinamismo. Nesse ponto, é preciso relacionar alguns elementos decisivos, e complementares, no processo de criação de conhecimento e acumulação de capacitações.

O primeiro desses fatores foram os provedores de máquinas e equipamentos, sobretudo italianos, para a indústria de revestimentos cerâmicos, já que eles se configuraram como uma fonte importante para a geração de conhecimento e para a inovação.

O segundo fator importante foram as interações com os fornecedores de insumos químicos, especialmente fritas e corantes utilizados nos revestimentos cerâmicos. Mais uma vez, as interações com os colorifícios representaram uma importante fonte de conhecimento, já que permitiram aos produtores de revestimentos incorporar novos padrões e novas características aos seus produtos.
Terceiro, deve-se apontar o papel das instituições de prestação de serviços aos produtores. Esse fenômeno foi verificado de modo particular no caso do sistema local de Santa Gertrudes, em que o centro tecnológico local teve papel fundamental na criação e difusão de novos conhecimentos entre os produtores locais.

Vale mencionar que a proximidade geográfica dos produtores, consubstanciada pela aglomeração dos agentes nos sistemas locais de produção, foi de fundamental importância para a criação e a difusão de novos conhecimentos técnicos e tecnológicos entre os produtores. A proximidade geográfica, como ocorre normalmente nessas estruturas produtivas localizadas, teve o papel de estimular a circulação dos conhecimentos, proporcionando aos produtores um conjunto de benefícios oriundos da aglomeração dos agentes.

Todavia, ao mesmo tempo em que é possível verificar a capacidade dos produtores em se apropriar dos benefícios da aglomeração industrial, as empresas demonstraram-se extremamente competentes no estabelecimento de canais de comunicação e de aprendizado junto a agentes não pertencentes aos sistemas locais. Isso fica evidente quando se percebe a existência e a importância dos vínculos globais dos produtores, tanto com os produtores de máquinas e equipamentos, quanto com os fornecedores de colorifícios. Esses elementos exerceram papel fundamental no fomento dos processos de aprendizado endógenos à firma.

\section{NOTAS}

1. Os dados apresentados nesta seção foram compilados a partir de informações coletadas junto à ASCER - Associação Espanhola de Fabricantes de Revestimentos Cerâmicos. Porém, os dados são apresentados em volume físico, isto é, produção em milhões de $\mathrm{m}^{2}$, e não em valor, como seria mais adequado.

2. Como esses produtos possuem uma baixa relação valor/ peso, o que torna esse produto pouco comercializável (tradeable) internacionalmente, o desenvolvimento das indústrias nacionais de revestimentos cerâmicos está normalmente associado à existência de uma demanda doméstica expressiva. Isso implica que todos os principais produtores são, ao mesmo tempo, grandes consumidores.

3. O processo de produção de revestimentos cerâmicos por via seca envolve um processo em que a argila é extraída da natureza, seca e moída, resultando na "massa pronta” adequada à prensagem. Já no processo por via úmida, a argila é hidratada, triturada e atomizada para que se possa retirar a água para a obtenção da "massa pronta". A principal di- 
ferença nesse sentido é a utilização, ou não, da água para a obtenção da "massa pronta".

4. Meyer-Stamer et al. (2004) chamaram o sistema local de Criciúma de sistema local de Santa Catarina, em referência ao estado em que ele está localizado e para incluir alguns produtores de revestimentos cerâmicos do estado que não estão localizados exatamente na região de Criciúma.

5. Um exemplo importante de uma empresa que abandonou as atividades de esmaltação foi da empresa Cecrisa, em que essa atividade gerou um spin-off, a Colorminas, que passou em 2000 a atuar como um colorifício independente, por meio do atendimento de diversas outras empresas de revestimentos cerâmicos, localizadas na região de Criciúma ou em outra região qualquer do país.

6. Esse foi o caso de uma das empresas mais importantes no segmento de máquinas para a indústria cerâmica do mundo, a italiana Sacmi, que projeta e fabrica máquinas e equipamentos para a indústria cerâmica, como atomizadores, prensas, fornos, matrizes e estampos. A empresa estabeleceu uma unidade própria no Brasil para o atendimento de seus usuários, especialmente no que se refere à oferta de peças para reposição.

7. Importante apontar a ausência de empresas de pequeno e médio porte no sistema local de Criciúma, já que uma das faces do processo de reestruturação da indústria local nos anos 1990 foi a forte concentração da oferta, seja pela falência, seja pela incorporação das empresas menores.
8. Dados da ASPACER mostram que o sistema local de Santa Gertrudes apresentou taxas de crescimento superiores a 10\% a.a. ao longo da década de 2000 , o que significa que a produção aumentou de 200 milhões de $\mathrm{m}^{2}$ no início da década para 366 milhões de $\mathrm{m}^{2} \mathrm{em}$ 2007. Essas taxas são significativamente superiores à média brasileira no mesmo período (em torno de $4 \%$ a.a.).

9. A obtenção de características técnicas inferiores no processo de via seca decorre principalmente da não atomização da massa, o que impede o completo espalhamento das partículas, o que prejudica a qualidade do produto final, além de gerar maior refugo.

10. Vale apontar que, como o processo de produção de revestimentos cerâmicos utiliza grande intensidade de energia, a economia de energia representada pelo processo "via seca" acaba exercendo papel muito importante para a redução de custos das empresas locais.

11. Todavia, a importância desse núcleo de inovação na área do design precisa ser contrastada com o baixo grau de utilização dos serviços que esse centro presta aos produtores locais. As visitas realizadas ao CITEC permitiram constatar que essa área do centro tecnológico é bastante ociosa.

12. Na Espanha, o coeficiente de exportações era pouco superior a $50 \%$ da produção doméstica em 2004, enquanto que na China, em virtude de seu vasto mercado consumidor, esse índice atingiu apenas $14 \%$ no mesmo ano.

\section{Artigo recebido em 10/09/2007 Aprovado para publicação em 15/09/2008}

\section{REFERÊNCIAS}

AMIN, A.; COHENDET, P. Architectures of Knowledge. Firms, Capabilities and Communities. Oxford: Oxford University Press, 2004.

ARROW, K. The Economic Implications of Learning-by-doing. The Review of Economic Studies, v. 29, n. 3, p. 155-173, 1962.

\section{ASSOCIAÇÃO NACIONAL DE FABRICANTES} DE CERÂMICA PARA REVESTIMENTO. Produção. Disponível em: http://www.anfacer.org.br. Data de acesso: 25 de março de 2008.
ASSOCIAÇÃO DOS PRODUTORES DE CERÂMICADEREVESTIMENTOSDAESPANHA. Disponível em: http://spaintiles.info/eng/index. asp. Data de acesso: 21 de dezembro de 2003.

AUDRESCHT, D.; FELDMAN, M. R\&D spillovers and the geography of innovation and production. The American Economic Review, v. 86, n. 3, 1996 .

BELUSSI, F.; PILOTTI, L. Knowledge Creation, Learning and Innovation in Italian Industrial Districts. Geografiska Annaler, 84B, p. 125139, 2002.
BELUSSI, F.; PILOTTI, L.; SEDITA, S. Learning at the boundaries for industrial districts between exploitation of local resources and the exploration of global knowledge flows. Working Paper n. 2006-40. Un. di Milano, 2006.

BRESCHI, S.; LISONI, F. Knowledge spillovers and local innovation systems: a critical survey'. Industrial and Corporate Change, n. 10, p. 975-1005, 2001.

COHEN, M.; LEVINTHAL, A. Absorptive Capacity a new perspective in Learning and Innovation. Administrative Science Quarterly, v. 35, n. 1, p. 128-152, 1990. 
DAVENPORT, H.; PRUSAK, L. Working Knowledge. Harvard Business School Press, 2000.

FERRAZ, G. Nota Técnica Final da Cadeia Cerâmica. In: COUTINHO, L. et al. (Coords). Estudo da Competitividade de Cadeias Integradas no Brasil: impactos das zonas de livre comércio. São Paulo: IE/NEIT/UNICAMP. Contrato MDIC/ MCT/FINEP, 2002.

GAMBULI, P. Tendências Mundiais da Produção de Revestimentos Cerâmicos. Cerâmica Industrial, v. 6, n. 6, nov. e dez, 2001.

GAVIGAN et al. Knowledge and Learning. The Futures Project of the European Commission Directorate, December, 1999.

LAM, A. Tacit Knowledge, Organizational Learning and Societal Institutions. An integrated Framework. Organizational Studies, v. 21 , n. 3 , p. $487-513,2000$.

LEMOS, A.; VIVONA, D. Visão Estratégica do Setor de Revestimentos Cerâmicos, Mercadológica e Tecnológica em Busca da
Consolidação da Competitividade Internacional. Cerâmica Industrial, v. 2, n. 3/4, 1997.

LUNDVALL, B.; JOHNSON, B. The Learning Economy. Journal of Industry Studies, v. 1, n. 2, p. 23-42, 1994

McDONALD, O.; BELUSSI, F. Industrial Districts a State of the Art Review. In: Project West and East "Industrial Districts" Re-Location Processes: Identifying Policies in the Perspective of the European Union Enlargement. September, Socio Economic Research, 2002.

MEYER-STAMER, J. et al. Upgrading in the Tile Industry of Italy, Spain and Brazil: insights from cluster and value chain analysis. In: SCHMITZ, H. (ed.) Local Enterprises in the Global Economy: Issues of Governance and Upgrading. Cheltenham: Edward Elgar 2004.

NONAKA, I.; TAKEUCHI, H. The Knowledgecreating Company. New York : Oxford University Press, 284p., 1995.

RUSSO, M. Technical Change and the Industrial District: The Role of Interfirm Relations in the Growth and
Transformation of Ceramic Tile Production in Italy. Research Policy, v. 14, n. 3, p. 329-343, 1985

SCUR, G.; GARCIA, R. Industrial Clusters in the Brazilian Ceramic Tile Industry and the New Challenges for Competition in the Global Value Chain. In: BELUSSI, F.; SAMARRA, A. Business Networks in Clusters and Industrial Districts: the Governance of the Global Value Chain. London: Routledge, 2008 (no prelo).

SASSI, S. A Indústria Cerâmica Mundial na Era da Globalização. Cerâmica Industrial, v. 11, n. 2 , março/abril, 2006.

TEECE, J. Capturing Value from Knowledge Assets. California management Review, v. 40, n. 3, p. 55-79, 1998.

TORRES, et al. Cooperação e Aprendizado em Arranjos Produtivos Locais. Rio de Janeiro, UFRJ, 2004 - disponível em: http://www.redesist. ie.ufrj.br. Acesso: 18 de maio de 2006

VON HAYEK, $F$. The Use of Knowledge in Society. The American Economic Review, v. 35 , issue 4, September, p. 519- 530, 1945

\section{SOBRE OS AUTORES}

\section{Gabriela Scur}

Departamento de Engenharia de Produção do Centro Universitário da FEI

End.: Av. Humberto Alencar Castelo Branco, 3972 - CEP 09850-901 - São Bernardo do Campo - SP

Tel.: 55 (11) 4353-2900

Fax: 55 (11) 4109-5994

E-mail: gabriela.sul@gmail.com

\section{Renato Garcia}

Departamento de Engenharia de Produção da Escola Politécnica da USP

End.: Av. Prof. Almeida Prado, Travessa 2, n. 128 - CEP 05508-070 - Cidade Universitária - São Paulo - SP

Tel.: 55 (11) 3091-5363

Fax: 55 (11) 3091-5399

E-mail: renato.garcia@poli.usp.br 


\section{ANEXO}

Tabela A1: Produção Mundial - em milhões de $\mathbf{m}^{2}$.

\begin{tabular}{|c|c|c|c|c|c|c|c|}
\hline & 2000 & 2001 & 2002 & 2003 & 2004 & 2005 & 2006 \\
\hline China & 1807 & 1810 & 1868 & 2000 & 2300 & 2500 & 3000 \\
\hline Espanha & 621 & 638 & 651 & 627 & 640 & 656 & 663 \\
\hline Brasil & 453 & 473 & 508 & 534 & 566 & 568 & 594 \\
\hline Itália & 632 & 638 & 606 & 603 & 589 & 570 & 569 \\
\hline Índia & 97 & 109 & 215 & 240 & 270 & 298 & 340 \\
\hline Indonésia & 200 & 220 & 230 & 260 & 260 & n.d. & n.d. \\
\hline Turquia & 175 & 155 & 163 & 189 & 216 & n.d. & n.d. \\
\hline México & 138 & 167 & 159 & 171 & 177 & n.d. & n.d. \\
\hline Vietnã & 55 & 95 & 105 & 110 & 165 & n.d. & n.d. \\
\hline Tailândia & 56 & 63 & 100 & 135 & 157 & n.d. & n.d. \\
\hline Resto dos países & 1216 & 1245 & 1337 & 1454 & 1531 & n.d. & n.d. \\
\hline TOTAL MUNDIAL & 5450 & 5614 & 5942 & 6323 & 6771 & & \\
\hline
\end{tabular}

Fonte: ASCER, 2006.

Mapa 1 - Principais aglomerações de produtores de revestimentos cerâmicos no Brasil.

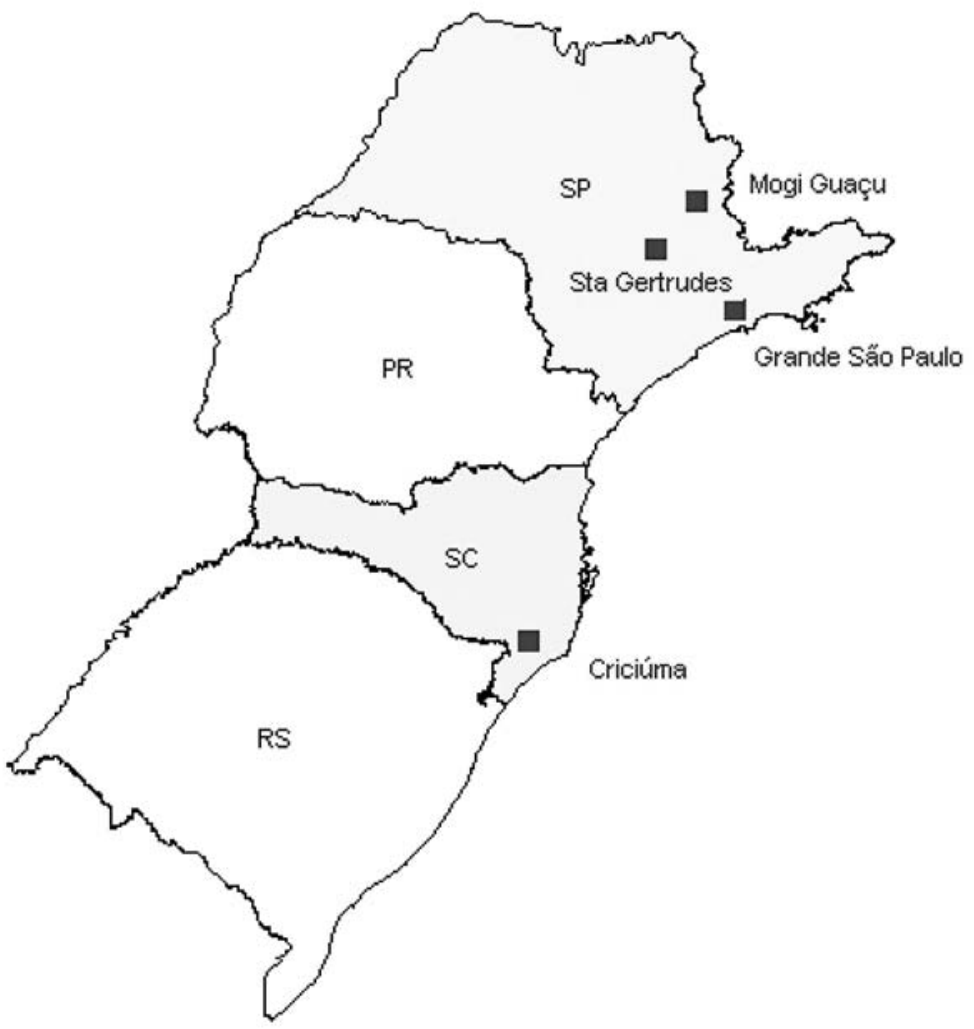

